\title{
A study on free-standing 3C-SiC bipolar power diodes
}

\author{
Fan Li ${ }^{* 1}$, Arne Benjamin Renz ${ }^{1}$, Amador Pérez-Tomás ${ }^{2}$, Vishal Shah ${ }^{1}$, \\ Peter Gammon ${ }^{1}$, Francesco La Via ${ }^{3}$, Mike Jennings ${ }^{4}$, and Phil Mawby ${ }^{1}$ \\ 1. School of Engineering, University of Warwick, Coventry CV4 7AL, U.K. (e-mail: f.li.3@warwick.ac.uk). \\ 2. Catalan Institute of Nanoscience and Nanotechnology (ICN2), CSIC and The Barcelona Institute of Science and Technology, \\ 3. Consiglio Nazionale delle Ricerche - Instituto per la Microelettronica e Microsistemi (CNR-IMM), Strada VIII, n.5 Zona \\ 4. College of Engineering, Swansea University, Swansea SA1 8EN, U.K.
} 08193 Barcelona, Spain. Industriale, 95121 Catania, Italy.

\begin{abstract}
A low p-n built-in potential (1.75 V) makes 3C-SiC an attractive choice for medium voltage bipolar or charge balanced devices. Until recently, most 3C-SiC had been grown on Si, and power device fabrication had therefore been hindered by issues such as high defect density and limited processing temperature, while devices were necessarily limited to lateral structures. In this work, we present the fabrication and characterisation of a vertical PiN diode using bulk 3C-SiC material. A p-type ohmic contact was obtained on $\mathrm{Al}$ implanted regions with a specific contact resistance $\sim 10^{-3} \Omega . \mathrm{cm}^{2}$. The fabricated PiN diode has a low forward voltage drop of $2.7 \mathrm{~V}$ at $1000 \mathrm{~A} / \mathrm{cm}^{2}$, and the on-off ratio at $\pm 3 \mathrm{~V}$ is as high as $10^{9}$. An ideality factor of 1.83-1.99 was achieved, and a blocking voltage of $\sim 110 \mathrm{~V}$ was observed using a singlezone junction termination design.
\end{abstract}

Index Terms-3C-SiC, PiN diode, forward voltage drop, post implant activation, leakage current

Wide bandgap (WBG) semiconductors are considered substrates for the next generation electronics, targeting high power and harsh environments that conventional Si devices struggle to meet. $4 \mathrm{H}-\mathrm{SiC}$ is currently the most mature wide bandgap technology, available with a range of commercial unipolar diodes and transistors up to $1700 \mathrm{~V}$. On the other hand, not as much work has been carried out on bipolar devices in $\mathrm{SiC}[1,2], \mathrm{Ga}_{2} \mathrm{O}_{3}[3]$, and diamond [4, 5]. WBG bipolar power devices are far less developed compared with their unipolar counterparts, mainly due to the issues related to deep level acceptor activation, high $\mathrm{p}-\mathrm{n}$ junction potentials and low minority carrier lifetime. Due to its narrower bandgap $E_{g_{-}}$C-sic of $2.3 \mathrm{eV}$ (at $300 \mathrm{~K}$ ) [6], 3C-SiC has a lower p-n junction built-in potential ( 1.75 V) than $4 \mathrm{H}-\mathrm{SiC}(\sim 3 \mathrm{~V})$. It is shown in [7] that $3 \mathrm{C}$-SiC PiN diodes rated up to $4.5 \mathrm{kV}$ have a forward voltage drop at $250 \mathrm{~A} / \mathrm{cm}^{2}$ lower than $4 \mathrm{H}-\mathrm{SiC}$. Until recently, however, the need to use $3 \mathrm{C}-\mathrm{SiC}$ grown on $\mathrm{Si}$ substrates has made power device fabrication difficult. This is due to the high defect density within these 3C-SiC epilayers [8, 9], and also due to the need to employ lateral architectures, in order to avoid the $3 \mathrm{C}-\mathrm{SiC} / \mathrm{Si}$ heterojunction. Low voltage lateral $\mathrm{p}$-n junction diodes were previously demonstrated by forming implanted regions in $3 \mathrm{C}$-SiC epilayers grown on Si substrates $[10,11]$. Furthermore, while there were several reports achieving p-type conduction in AI doped 3C-SiC epilayers [12-14], it remains an obstacle for implanted layers, which is often required in edge termination and JBS designs. This is mainly due to the post implantation anneal temperature, which is limited to the $1414^{\circ} \mathrm{C}$ (melting point of $\mathrm{Si}$ ), thus not sufficient to activate the deep level Al dopants. In [15], p-type conduction was realised after Al was implanted $\left(200 \mathrm{keV}, 8 \times 10^{14} \mathrm{~cm}^{-2}\right.$, peak doping $\left.\sim 5 \times 10^{19} \mathrm{~cm}^{-3}\right)$ into $3 \mathrm{C}$-SiC at high temperature $\left(850^{\circ} \mathrm{C}\right)$ followed by a $1400{ }^{\circ} \mathrm{C}$ post implant anneal, although the activation rate was estimated to be as low as $1 \%$. With lower temperature $\mathrm{Al}$ implantation $\left(50{ }^{\circ} \mathrm{C} ; 180 / 110 / 60 / 30 \mathrm{keV}\right.$, $11.2 / 7 / 5 / 2.7 \times 10^{14} \mathrm{~cm}^{-2}$, peak doping $\left.\sim 1 \times 10^{20} \mathrm{~cm}^{-3}\right)$ and anneal $\left(1300{ }^{\circ} \mathrm{C}\right)$, it was shown that in $\mathrm{Al}$ implanted $3 \mathrm{C}$-SiC layers, $\mathrm{p}$-type conduction could only be achieved after a very long anneal $(>317 \mathrm{~h})$ [16]. Studies on 3C-SiC growth methods in recent years led to a continuous reduction of defect density, and free standing 3C-SiC wafers were demonstrated [17-21]. By removing the Si substrates (polish, etch, melt, etc.), the left-over $3 \mathrm{C}-\mathrm{SiC}$ wafer not only keeps the large area desired for lowering device 
costs, but also a higher processing temperature can be achieved. In addition, without the heterojunction, a vertical structure becomes possible, making the most of $3 \mathrm{C}$-SiC in power device applications. In this work, by fabricating edge terminated, vertical power PiN diodes on bulk 3C-SiC wafers, both $p$-type conduction and high voltage ( $>100 \mathrm{~V}) \mathrm{p}$-n junction blocking is demonstrated.

To obtain the bulk 3C-SiC material used in this work, first, $150 \mu \mathrm{m}$ intentionally nitrogen doped $\left(1 \times 10^{18} \mathrm{~cm}^{-3}\right)$ n-type $3 \mathrm{C}$-SiC was grown on Si(100) substrates via Chemical Vapour Deposition (CVD). Next, the chamber temperature was increased to $1750^{\circ} \mathrm{C}$ to melt and remove the $\mathrm{Si}(100)$ substrate. Another $10 \mu \mathrm{m}$ thick non-intentionally doped $\left(\sim 2.5 \times 10^{16} \mathrm{~cm}^{-3}\right)$ n-type $3 \mathrm{C}$-SiC epilayer was then grown on the highly doped $3 \mathrm{C}-\mathrm{SiC}$ substrate. More detailed information about the bulk 3C-SiC growth can be found in $[21,22]$. TEM analysis suggested that the resulting stacking fault density of these homoepitaxial grown $3 \mathrm{C}$-SiC layers is below $10^{3} \mathrm{~cm}^{-1}$ [22], which is among the lowest values obtained using various techniques, including standard $\mathrm{Si}$ substrate, inverted silicon pyramids substrate, and lower temperature $\left(1400{ }^{\circ} \mathrm{C}\right)$ homoepitaxy growth [18]. Polishing of the as-grown 3C-SiC surface was challenging due to the stress and bowing within the wafer $[23,24]$ thus was not carried out. By performing a tapping mode AFM scan in several $10 \mu \mathrm{m} \times 10 \mu \mathrm{m}$ areas, RMS surface roughness around $10 \mathrm{~nm}$ was observed.

The PiN diode fabrication began with two box-profile Al implantations, both performed at $600{ }^{\circ} \mathrm{C}$. First a $350 \mathrm{~nm}$ deep, highly doped $\left(1 \times 10^{20} \mathrm{~cm}^{-3}\right) \mathrm{p}$ + anode region $\left(180 / 100 / 40 \mathrm{keV}, 20 / 10 / 5 \times 10^{14} \mathrm{~cm}^{-2}\right)$ was formed. Second, a $600 \mathrm{~nm}$ deep, p-doped $\left(2 \times 10^{17} \mathrm{~cm}^{-3}\right)$ Single-Zone Junction Termination

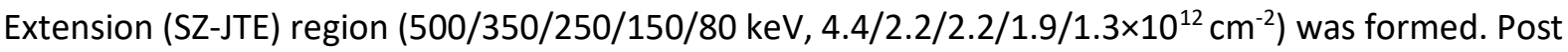
implantation anneals were performed at $1700{ }^{\circ} \mathrm{C}$ for 2 hours in $\mathrm{Ar}$, with the sample surface covered by a carbon cap, which was then removed by oxidation in dry $\mathrm{O}_{2}$ at $850^{\circ} \mathrm{C}$ for 30 minutes. Following that, the samples went through standard RCA 1 and 2 cleaning procedures and were thermally oxidised in dry $\mathrm{O}_{2}$ at $1300^{\circ} \mathrm{C}$ to form a thin $\mathrm{SiO}_{2}$ layer $(\approx 75 \mathrm{~nm})$, which passivates the surface dangling bonds and isolates the devices. With the top surface protected by a layer of baked photoresist, the back side $\mathrm{SiO}_{2}$ was removed by wet etch (HF), after which, a Ti/Ni (30/100 nm) bilayer was evaporated onto the $\mathrm{n}+$ substrate and annealed at $1000{ }^{\circ} \mathrm{C}$ for 1 minute in Ar to form the cathode [25]. Via photolithography, the surface passivation $\mathrm{SiO}_{2}$ was selectively wet etched in diluted HF, circular $\mathrm{Ti} / \mathrm{Al} / \mathrm{Ni}(30 / 100 / 50 \mathrm{~nm})$ metal stacks with $40 \mu \mathrm{m}$ diameter were then evaporated and lifted-off as the anodes [12]. To form ohmic contact, the anodes went through a rapid thermal anneal at $1100^{\circ} \mathrm{C}$ for 2 minutes in Ar. A cross sectional view of the final device with a circular structure is shown in Fig. 1.

Fig. 1. Schematic cross section view of the fabricated free-standing 3C-SiC PiN diode with Single Zone Junction Termination Extensions (SZ-JTE).

TLM structures were fabricated in the $\mathrm{p}+$ implanted regions, and their room temperature I-V characteristics are shown in Fig. 2. Ohmic behaviour is observed and the lowest specific contact resistance is $\sim 9.7 \times 10^{-4} \Omega . \mathrm{cm}^{2}$. Not only is this among the lowest values recently reported for $p$-type 3 C-SiC $[12,16]$, but also the post implant anneal time is significantly reduced from $>300$ hours to a more practical 2 hours. However, the extracted specific contact resistance $\left(10^{-4}-10^{-2} \Omega . \mathrm{cm}^{2}\right)$ and sheet resistance (2500-15000 $\Omega / \mathrm{sq}$ ) values have a large distribution. This is most likely due to the rough surface previously mentioned and can be improved by optimising the growing conditions and polishing methods.

Fig. 2. Room temperature I-V characterisation of the p-type ohmic contact TLM and fitting of the total resistance.

Typical room temperature forward J-V characteristics of the PiN diodes are shown in Fig. 3a, and the built-in potential can be extracted from the intersection of forward current linear region fitting and the $\mathrm{x}$-axis, which is just above $2 \mathrm{~V}$, slightly higher than the theoretical value $1.75 \mathrm{~V}$, but still $33 \%$ lower than the $3 \mathrm{~V}$ of typical $4 \mathrm{H}$-SiC PiN diodes $[1,2,26]$. The current density goes above $1000 \mathrm{~A} / \mathrm{cm}^{2}$ at $2.7 \mathrm{~V}$ forward bias and hits the measurement compliance $\left(5000 \mathrm{~A} / \mathrm{cm}^{2}\right)$ at $\sim 4.5 \mathrm{~V}$. Device selfheating is inevitable at such high current density. At elevated temperatures, SiC carrier lifetime was 
found to increase exponentially, while the carrier mobility and diffusion coefficients decrease [27]. It was shown in [28] that significant degradation occurred to $4 \mathrm{H}-\mathrm{SiC}$ PiN diodes above $1700 \mathrm{~A} / \mathrm{cm}^{2}$, and a $9000 \mathrm{~A} / \mathrm{cm}^{2}, 8-\mathrm{ms}$ pulse can heat the device to 2000-2300 K. Carrier transportation in SiC in extreme conditions such as in this work is not yet well understood and needs further investigations. The differential specific on-resistance is estimated to be $\sim 0.5 \mathrm{~m} \Omega . \mathrm{cm}^{2}$, and the on-off ratio at $\pm 3 \mathrm{~V}$ is greater than $10^{9}$ as shown in Fig. $3 \mathrm{~b}$.

Fig. 3. Typical (a) 0-5 V forward J-V characteristics and (b) $\pm 3 \vee$ on-off performance of PiN diodes at room temperature.

The built-in potential can be estimated from the second knee in the semi logarithmic graph (Fig. 4a), where the series resistance begins to dominate the forward conduction. A double-bump feature is consistently observed in the forward semi-log scale J-V curve (Fig. 4a). This is usually due to an inhomogeneous interface [29, 30], which causes multiple current paths with different barrier heights, affecting the conduction mechanism. The diode ideality factor $n$ can be extracted from the high-level injection region, and the typical values are 1.83-1.99, indicating the current transport is dominated by recombination. This latest result shows great improvements from literature, where either too large $(n>3,[31,32])$ or too small values $(n \approx 1.5,[11])$ were observed. In the low-level injection region, ideality factors $>2$ were obtained, this is most likely due to defect induced carrier recombination [33].

Fig. 4. Typical semi-log scale J-V characteristics of (a) forward and (b) reverse biased PiN diodes at room temperature.

At high reverse bias, the diodes suffer from a high leakage current density $J_{r}$, reaching $0.1 \mathrm{~mA} / \mathrm{cm}^{2}$ at $-10 \mathrm{~V}$ as seen in Fig. $4 \mathrm{~b}$. $J_{r}$ does not follow a square root dependence (space-charge generation dominant) on the reverse bias. Instead, $J_{r} \propto V^{\alpha}$, where $\alpha \approx 6.7$ from 0 to $-50 \mathrm{~V}$. The fast increasing leakage is most likely due to defect assisted tunneling. It is known that stacking faults are the main cause of the high leakage in 3C-SiC devices [34, 35], and in order to achieve a low $J_{r}$ of $\sim 0.1 \mathrm{~mA} / \mathrm{cm}^{2}$ at $-600 \mathrm{~V}$, stacking fault density needs to be kept below $700 \mathrm{~cm}^{-1}$ [9]. Also, the fact $J_{r}$ is above $0.1 \mathrm{~mA} / \mathrm{cm}^{2}$ at $-10 \mathrm{~V}$ means self-heating cannot be neglected here, which can raise the leakage current level further [36]. Further increasing the reverse bias, the $\alpha$ value drops to $~ 4.1$. A maximum blocking voltage of $\sim 110 \mathrm{~V}$ was achieved (Fig. 4b). Assuming a critical field for $3 \mathrm{C}-\mathrm{SiC}$ of $1.4 \mathrm{MV} / \mathrm{cm}$ [37], the theoretical $1 \mathrm{D}$ breakdown of the device is $210 \mathrm{~V}$, occurring at a depletion region depth $3 \mu \mathrm{m}$ from the surface. These devices therefore achieve $\sim 50 \%$ of the $1 \mathrm{D}$ theoretical value for this drift layer, further demonstrating the scope for improvement in the surface quality and termination.

At elevated temperatures $(300-500 \mathrm{~K})$, the forward current density increases, and the built-in potential decreases as shown in Fig. $5 \mathrm{a}$, which is due to the increasing number of intrinsic carriers. As can be seen from the linear plot inset (Fig. 5a), at relatively low current density $\left(<60 \mathrm{~A} / \mathrm{cm}^{2}\right)$, the forward J-V curves are parallel to each other, indicating a temperature independent differential resistance. Similar behaviour was previously observed for $4 \mathrm{H}-\mathrm{SiC}$ PiN diodes [36], the result of compensation between an increase in carrier lifetime and a decrease in mobility and the diffusion coefficients. The low voltage ( 0 to $-2 \mathrm{~V}$ ) leakage current density increases significantly with increasing measurement temperature, from $\sim 1 \times 10^{-7} \mathrm{~A} / \mathrm{cm}^{2}$ at $25{ }^{\circ} \mathrm{C}$ to $\sim 1 \times 10^{-4} \mathrm{~A} / \mathrm{cm}^{2}$ at $225{ }^{\circ} \mathrm{C}$. Despite the leakage being dominated by defect assisted tunnelling, the thermally-generated component, the saturation current density $J_{0}$, can be extracted from the high-level injection region (Fig. 5a), and the Arrhenius plot is shown in Fig. $5 \mathrm{~b}$. The activation energy for the thermally-generated leakage component is estimated to be $\sim 0.88 \mathrm{eV}$, still lower than $E_{g_{-} 3 c-s i c} / 2 \approx 1.15 \mathrm{eV}$, in which case it is considered that carrier transportation is dominated by recombination. This is likely due to a tunnelling contribution to the carrier transportation which still cannot be neglected, even in the high-level injection $\left(\sim 100 \mathrm{~A} / \mathrm{cm}^{2}\right)$ regime, thus leading to a lower activation energy than expected. 
Fig. 5. PiN diode (a) log scale forward J-V characteristics at 300-500K. and (b) the saturation current density Jo Arrhenius plot.

A figure of merit (FoM) graph of $\mathrm{Si}, 3 \mathrm{C}-\mathrm{SiC}$, and $4 \mathrm{H}-\mathrm{SiC}$ for power device applications is shown in Fig. 6 with some literature data of 3C-SiC unipolar devices [14, 38-40] due to lack of bipolar device results. As can be seen, the PiN diode fabricated in this work currently betters both the Si unipolar and superjunction limits. Also, improvement over the $3 \mathrm{C}$-SiC MOSFETs and SBD can be inferred, because as the voltage rating is scaled up, the rise in on-resistance of these bipolar devices will be less than the unipolar devices. Furthermore, simple improvements can be made to these bulk 3C-SiC vertical PiN diodes to further improve this picture. Reducing the drift layer thickness to the maximum reverse depletion width ( $3 \mu \mathrm{m}$ in this case), would have substantially lowered the on-resistance. Furthermore, lowering the drift layer doping $\left(<1 \times 10^{16} \mathrm{~cm}^{-3}\right)$, smoothing the surface, and improving upon the junction termination process (use of P-Ring, or trench terminations) would all result in an increased breakdown voltage. However, there remains an evident gap between current $3 \mathrm{C}$-SiC power device performance and the $3 \mathrm{C}$-SiC unipolar limit, which needs will be narrowed in the near future via follow up studies on defect density reduction and device processing.

Fig. 6. Power device figure of merit graph for $\mathrm{Si}, 3 \mathrm{C}-\mathrm{SiC}$, and $4 \mathrm{H}-\mathrm{SiC}$, literature $3 \mathrm{C}$-SiC devices parameters are provided [14, 37-39].

Vertical PiN diodes have been fabricated using Al implantation into bulk 3C-SiC material. Removal of the Si substrate made possible post-implantation annealing at $1700^{\circ} \mathrm{C}$, making the development of a p-type ohmic contact more practically realisable. The diodes showed good on-state performance, with a reasonable ideality factor of $1.83-1.99$. Despite of a very high on-off ratio $\left(\sim 10^{9}\right)$ at $\pm 3 \mathrm{~V}$, considerable defect assisted tunnelling was observed at higher reverse bias. The thermally-generated leakage component was found to be dominated by space charge generation, with an activation energy of $\sim 0.88 \mathrm{eV}$. Limited by the defect density and surface roughness, the maximum blocking voltage reached in this work is $\sim 110 \mathrm{~V}$, but achieving $1000 \mathrm{~A} / \mathrm{cm}^{2}$ with a low forward voltage drop of $2.7 \mathrm{~V}$ demonstrates the potential of using $3 \mathrm{C}$-SiC for PiN and MPS power diodes applications.

This work was supported in part by the European Commission through the Challenge Project under Grant ID 720827.

The data that support the findings of this study are available from the corresponding author upon reasonable request.

\section{REFERENCES}

[1] C. A. Fisher, M. R. Jennings, Y. K. Sharma, D. P. Hamilton, P. M. Gammon, A. Pérez-Tomás, S. M. Thomas, S. E. Burrows, P. A. Mawby, "Improved performance of $4 \mathrm{H}-\mathrm{SiC}$ PiN diodes using a novel combined high temperature oxidation and annealing process," IEEE Trans. Semicond. Manuf., vol. 27, no. 3, pp. 443-451, 2014. doi: 10.1109/tsm.2014.2336701.

[2] Y. Bu, H. Yoshimoto, N. Watanabe, and A. Shima, "Fabrication of $4 \mathrm{H}-\mathrm{SiC}$ PiN diodes without bipolar degradation by improved device processes," J. Appl. Phys., vol. 122, no. 24, p. 244504, 2017. doi: 10.1063/1.5001370.

[3] M. M. Islam, M. O. Liedke, D. Winarski, M. Butterling, A. Wagner, P. Hosemann, Y. Wang, B. Uberuaga, and F. A. Selim, "Chemical manipulation of hydrogen induced high p-type and n-type conductivity in $\mathrm{Ga}_{2} \mathrm{O}_{3}$," Sci. Rep., vol. 10, no. 1, p. 6134, 2020. doi: 10.1038/s41598-020-62948-2.

[4] M. Saremi, R. Hathwar, M. Dutta, F. A. Koeck, R. J. Nemanich, S. Chowdhury, and S. M. Goodnick, "Analysis of the reverse I-V characteristics of diamond-based PIN diodes," Appl. Phys. Lett., vol. 111, no. 4, p. 043507, 2017. doi: 10.1063/1.4986756.

[5] J. Holmes, M. Dutta, F. A. Koeck, M. Benipal, J. Brown, B. Fox, R. Hathwar, H. Johnson, M. Malakoutian, M. Saremi, A. Zaniewski, R. Alarcon, S. Chowdhury, S. M. Goodnick, and R. J. Nemanich, "A 4.5 $\mu \mathrm{m}$ PIN diamond diode for detecting slow neutrons," Nucl. Instrum. Methods. 
Phys. Res. B NUCL INSTRUM METH A, vol. 903, pp. 297-301, 2018. doi: 10.1016/j.nima.2018.06.061.

[6] M. E. Levinshtein, S. L. Rumyantsev, and M. S. Shur, Properties of Advanced Semiconductor Materials: GaN, AIN, InN, BN, SiC, SiGe. John Wiley \& Sons, 2001.

[7] A. E. Arvanitopoulos, M. Antoniou, S. Perkins, M. Jennings, M. B. Guadas, K. N. Gyftakis, and N. Lophitis, "On the suitability of $3 \mathrm{C}$-silicon carbide as an alternative to $4 \mathrm{H}$-silicon carbide for power diodes," IEEE Trans. Ind., vol. 55, no. 4, pp. 4080-4090, 2019. doi: 10.1109/tia.2019.2911872.

[8] F. Giannazzo, G. Greco, S. Di Franco, P. Fiorenza, I. Deretzis, A. La Magna, C. Bongiorno, M. Zimbone, F. La Via, M. Zielinski, and F. Roccaforte, "Impact of stacking faults and domain boundaries on the electronic transport in cubic silicon carbide probed by conductive atomic force microscopy," Adv. Electron. Mater., vol. 6, no. 2, 1901171, 2020. doi: 10.1002/aelm.201901171.

[9] H. Nagasawa, T. Kawahara, K. Yagi, and N. Hatta, "Propagation of stacking faults in 3C-SiC," Mater. Sci. Forum, vol. 679, pp. 282-285, 2011. doi: 10.4028/www.scientific.net/MSF.679-680.282.

[10] K. Shibahara, T. Takeuchi, S. Nishino, and H. Matsunami, "Electrical properties of undoped and ion-implanted cubic SiC grown on $\mathrm{Si}(100)$ by chemical vapor deposition," Jpn. J. Appl. Phys., vol. 28, no. 8, pp. 1341-1347, 1989. doi: 10.1143/jjap.28.1341.

[11] R. Tyagi and T. P. Chow, "Self-enclosed vs. LOPOS-terminated lateral planar $p+/ n$ and $n+/ p$ junctions in 3C-SiC/Si," presented in 8th International Symposium on Power Semiconductor Devices and ICS, pp. 115-118, 1996. doi: 10.1109/ISPSD.1996.509461.

[12] M. Spera, G. Greco, R. Lo Nigro, C. Bongiorno, F. Giannazzo, M. Zielinski, F. La Via, and F. Roccaforte, "Ohmic contacts on n-type and p-type cubic silicon carbide (3C-SiC) grown on silicon," Mater. Sci. Semicond. Process., vol. 93, pp. 295-298, 2019. doi: 10.1016/j.mssp.2019.01.015.

[13] L. Wang, S. Dimitrijev, J. Han, P. Tanner, A. lacopi, and L. Hold, "Demonstration of p-type 3C-SiC grown on $150 \mathrm{~mm} \mathrm{Si}(100)$ substrates by atomic-layer epitaxy at $1000^{\circ} \mathrm{C}$," J. Cryst. Growth, vol. 329, no. 1, pp. 67-70, 2011. doi: 10.1016/j.jcrysgro.2011.06.041.

[14] M. Abe, H. Nagasawa, P. Ericsson, H. Strömberg, M. Bakowski, and A. Schöner, "High current capability of 3C-SiC vertical DMOSFETs," Microelectron. Eng., vol. 83, no. 1, pp. 24-26, 2006. doi: 10.1016/j.mee.2005.10.017.

[15] M. V. Rao and P. Griffths, "Al and B ion-implantations in 6H- and 3C-SiC," J. Appl. Phys., vol. 77, no. 6, pp. 2479-2485, 1995. doi: 10.1063/1.358776.

[16] R. Nipoti, M. Canino, M. Zielinski, F. Torregrosa, and A. Carnera, " $1300^{\circ} \mathrm{C}$ annealing of $1 \times 10^{20}$ $\mathrm{cm}^{-3} \mathrm{Al}^{+}$ion implanted 3C-SiC/Si," ECS J. Solid State Sci. Technol., vol. 8, no. 9, pp. 480-487, 2019. doi: 10.1149/2.0121909jss.

[17] N. Hatta, T. Kawahara, K. Yagi, H. Nagasawa, S. A. Reshanov, and A. Schöner, "Reliable method for eliminating stacking fault on 3C-SiC (001)," Mater. Sci. Forum., vol. 717, pp. 173-176, 2012. doi: 10.4028/www.scientific.net/msf.717-720.173.

[18] F. La Via, A. Severino, R. Anzalone, C. Bongiorno, G. Litrico, M. Mauceri, M. Schoeler, P. Schuh, and P. Wellmann, "From thin film to bulk 3C-SiC growth: understanding the mechanism of defects reduction," Mater. Sci. Semicond. Process., vol. 78, pp. 57-68, 2018. doi: 10.1016/j.mssp.2017.12.012.

[19] G. Fisicaro, C. Bongiorno, I. Deretzis, F. Giannazzo, F. La Via, F. Roccaforte, M. Zielinski, M. Zimbone, and A. La Magna, "Genesis and evolution of extended defects: the role of evolving interface instabilities in cubic SiC," Appl. Phys. Rev., vol. 7, no. 2, 021402, 2020. doi: 10.1063/1.5132300.

[20] H. Nagasawa and K. Yagi, "3C-SiC single-crystal films grown on 6-inch Si substrates," Phys. Status. Solidi. B, vol. 202, no. 1, pp. 335-358, 1997. doi:10.1002/1521-3951(199707)202:1<335:AIDPSSB335>3.0.CO;2-Y.

[21] F. La Via, M. Mauceri, V. Scuderi, C. Calabretta, M. Zimbone, and R. Anzalone, "3C-SiC bulk growth: effect of growth rate and doping on defects and stress," Mater. Sci. Forum., vol. 1004, pp. 120-125, 2020. doi: 10.4028/www.scientific.net/msf.1004.120. 
[22] R. Anzalone, M. Zimbone, C. Calabretta, M. Mauceri, A. Alberti, R. Reitano, F. La Via, "Temperature investigation on 3C-SiC homo-epitaxy on four-inch wafers," Materials (Basel), vol. 12 , no. 20 , p. 3293 , 2019. doi: $10.3390 /$ ma12203293.

[23] M. Zielinski, S. Ndiaye, T. Chassagne, S. Juillaguet, R. Lewandowska, M. Portail, A. Leycuras, and J. Camassel, "Strain and wafer curvature of $3 \mathrm{C}-\mathrm{SiC}$ films on silicon: influence of the growth conditions," Phys. Status. Solidi. A, vol. 204, no. 4, pp. 981-986, 2007. doi: 10.1002/pssa.200674130.

[24] B. E. Watts, G. Attolini, T. Besagni, M. Bosi, C. Ferrari, F. Rossi, F. Riesz, and L. D. Jiang, "Evaluation of curvature and stress in 3C-SiC grown on differently oriented Si substrates," Mater. Sci. Forum, vol. 679-680, pp. 137-140, 2011. doi: 10.4028/www.scientific.net/msf.679-680.137.

[25] F. Li, Y. Sharma, V. Shah, M. Jennings, A. Pérez-Tomás, M. Myronov, C. Fisher, D. Leadley, and P. Mawby, "Electrical activation of nitrogen heavily implanted 3C-SiC(100)," Appl. Surf. Sci., vol. 353, pp. 958-963, 2015. doi: 10.1016/j.apsusc.2015.06.169.

[26] R. Singh, J. A. Cooper, M. R. Melloch, T. P. Chow, and J. W. Palmour, "SiC power Schottky and PiN diodes," IEEE Trans. Electron Devices, vol. 49, no. 4, pp. 665-672, 2002. doi: 10.1109/16.992877.

[27] P. Ivanov, M. Levinshtein, K. Irvine, O. Kordina, J. Palmour, S. Rumyantsev, and R. Singh, "High hole lifetime $(3.8 \mu \mathrm{s})$ in $4 \mathrm{H}-\mathrm{SiC}$ diodes with $5.5 \mathrm{kV}$ blocking voltage," Electron. Lett., vol. 35, pp. 1382-1383, 1999. doi:10.1049/el:19990897.

[28] M. E. Levinshtein, T. T. Mnatsakanov, P. A. Ivanov, J. W. Palmour, M. K. Das, and B. A. Hull, "Selfheating of $4 \mathrm{H}-\mathrm{SiC}$ PiN diodes at high current densities," Mater. Sci. Forum, vol. 600-603, pp. 10071010, 2009. doi: 10.4028/www.scientific.net/MSF.600-603.1007.

[29] G. Brezeanu, G. Pristavu, F. Draghici, M. Badila, and R. Pascu, "Characterization technique for inhomogeneous 4H-SiC Schottky contacts: A practical model for high temperature behavior," J. Appl. Phys., vol. 122, no. 8, 084501, 2017. doi: 10.1063/1.4999296.

[30] P. M. Gammon, A. Perez-Tomas, V. A. Shah, O. Vavasour, E. Donchev, J. S. Pang, M. Myronov, C. A. Fisher, M. R. Jennings, D. R. Leadley, and P. A. Mawby, "Modelling the inhomogeneous SiC Schottky interface," J. Appl. Phys., vol. 114, no. 22, 223704, 2013. doi: 10.1063/1.4842096.

[31] K. Furukawa, A. Uemoto, M. Shigeta, A. Suzuki, and S. Nakajima, "3C-SiC p-n junction diodes," Appl. Phys. Lett., vol. 48, no. 22, pp. 1536-1537, 1986. doi: 10.1063/1.96860.

[32] P. G. Neudeck, D. J. Larkin, J. E. Starr, J. A. Powell, C. S. Salupo, and L. G. Matus, "Electrical properties of epitaxial 3C- and 6H-SiC p-n junction diodes produced side-by-side on $6 \mathrm{H}-\mathrm{SiC}$ substrates," IEEE Trans. Electron Devices, vol. 41, no. 5, pp. 826-835, 1994. doi: 10.1109/16.285038.

[33] N. A. Modine, A. M. Armstrong, M. H. Crawford, and W. W. Chow, "Highly nonlinear defectinduced carrier recombination rates in semiconductors," J. Appl. Phys., vol. 114, no. 14, p. 144502, 2013. doi: $10.1063 / 1.4824065$.

[34] A. Boulle, D. Chaussende, L. Latu-Romain, F. Conchon, O. Masson, and R. Guinebretière, "X-ray diffuse scattering from stacking faults in thick 3C-SiC single crystals," Appl. Phys. Lett., vol. 89, no. 9, 091902, 2006. doi: 10.1063/1.2338787.

[35] K. Yagi, T. Kawahara, N. Hatta, and H. Nagasawa, "'Switch-back epitaxy'as a novel technique for reducing stacking faults in 3C-SiC," in Mater. Sci. Forum, vol. 527, pp. 291-294, 2006. doi: 10.4028/www.scientific.net/msf.527-529.291.

[36] M. E. Levinshtein, P. A. Ivanov, M. S. Boltovets, V. A. Krivutsa, J. W. Palmour, M. K. Das, B. A. Hull, "High-temperature (up to 773K) operation of $6 \mathrm{kV} 4 \mathrm{H}-\mathrm{SiC}$ junction diodes," Solid State Electron., vol. 49, no. 7, pp. 1228-1232, 2005. doi: 10.1016/j.sse.2005.04.020.

[37] H. Nagasawa, M. Abe, K. Yagi, T. Kawahara, and N. Hatta, "Fabrication of high performance 3C$\mathrm{SiC}$ vertical MOSFETs by reducing planar defects," Phys. Status. Solidi. B, vol. 245, no. 7, pp. $1272-$ 1280, 2008. doi: 10.1002/pssb.200844053.

[38] M. Bakowski, A. Schöner, P. Ericsson, H. Strömberg, H. Nagasawa, and M. Abe, "Development of 3C-SiC MOSFETs," J. Telecommun. Inf. Technol., vol. 2, pp. 49-56, 2007. 
[39] P. Shenoy, A. Moki, B. J. Baliga, D. Alok, K. Wongchotigul, and M. Spencer, "Vertical Schottky barrier diodes on $3 \mathrm{C}-\mathrm{SiC}$ grown on $\mathrm{Si}$," presented in IEEE International Electron Devices Meeting, 4891443, 1994. doi: 10.1109/iedm.1994.383380. 